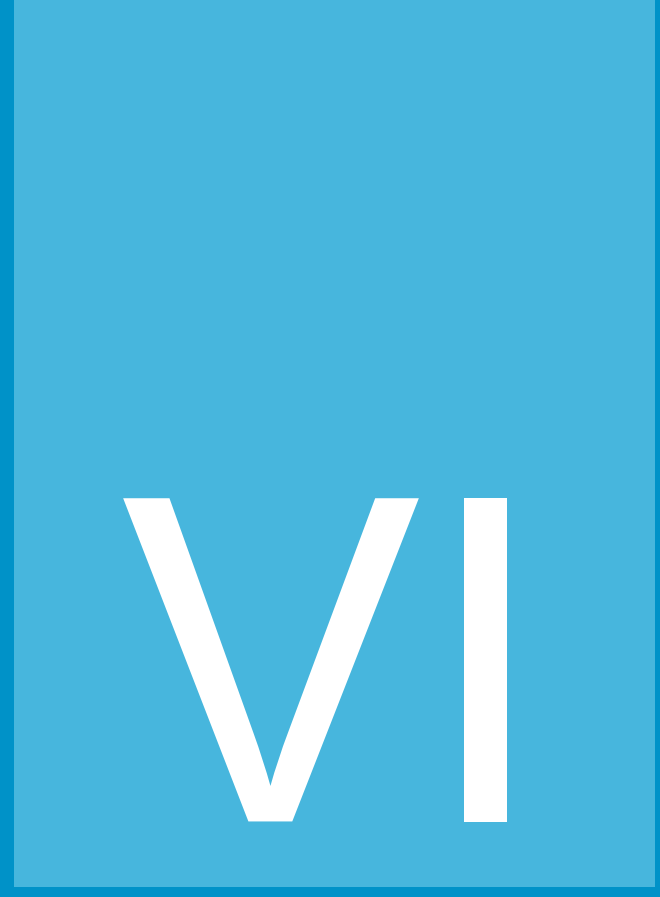

\title{
ÉTICA, LIDERAZGO Y COSMOVISIÓN BÍBLICA FRENTE A LA COSMOVISIÓN NATURALISTA
}

\section{Ethics, leadership and biblical worldview against the naturalistic worldview}

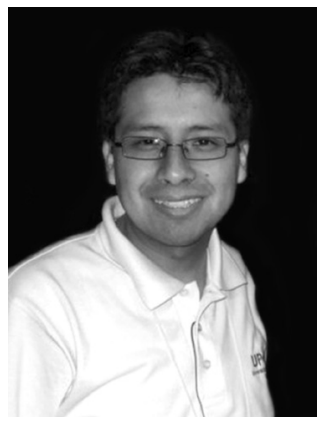

\section{Joel Ricardo Turpo}

Licenciado en Teología por la Universidad Peruana Unión. Magíster en Teología por el SALT, doctorando en Teología Sistemática por la Universidad Adventista del Plata, Argentina. Escritor y conferenciante a nivel nacional e internacional. Actualmente se desempeña como director del Centro de Investigación en Geosciencia de la Universidad Peruana Unión. 


\section{Resumen}

El autor explora la relación entre cosmovisión y ética, para luego analizar las diferencias e implicaciones éticas entre la cosmovisión bíblica y naturalista. Para ello se vale del estudio de la concepción del hombre, su conciencia moral, su discernimiento de las leyes, su percepción del tiempo y su diferencia con los animales. El propósito es mostrar que tanto la cosmovisión naturalista como la bíblica tienen un impacto ético, congruente o incongruente, en todas las categorías de la existencia humana y el continuum de la historia.

Palabras clave: Ética; cosmovisión, naturalismo.

\section{Abstract}

The author explores the relationship between worldview and ethics, and then analyzes the differences and ethical implications between the biblical worldview and naturalist. In doing that, he studies the concept of man, his conscience, his discernment of the laws, their perception of time and its difference with animals. The purpose is to show that both, the naturalistic worldview and the biblical worldview, ethical impact, consistent or inconsistent, in all categories of human existence and the continuum of history.

Keywords: Ethics worldview, naturalism. 


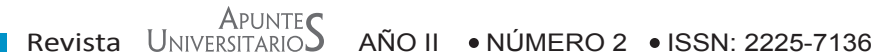

\section{Introducción}

La cosmovisión, sea cual fuere, no es opcional, todos los seres humanos pensamos y actuamos sobre la base de una cosmovisión, aunque no seamos conscientes de ello (Fowler, 1990). Así, sea cual fuera la conducta ética, ésta se fundamenta en una cosmovisión particular de la vida. En consecuencia, es fundamental examinar el significado de la cosmovisión y su relación con la ética, para identificar los valores y actitudes que la gobiernan.

Por lo cual, el presente estudio, examina (1) la relación entre la cosmovisión y la ética, (2) conceptualizando las diferencias entre la cosmovisión bíblica y naturalista, (3) comparando las implicaciones éticas basadas en su (a) concepción del hombre, (b) su diferencia con los animales, (c) el desarrollo de su conciencia, (d) su discernimiento de las leyes, y finalmente (e) su percepción del tiempo. Se pretende mostrar que tanto la cosmovisión naturalista como la bíblica tienen un impacto ético, sea coherente o incoherente, en todas las categorías de la existencia humana.

\section{Relación entre la ética y la cosmovisión}

La ética es el estudio de los valores morales y de la conducta que procura contestar ciertas cuestiones fundamentales que todos enfrentamos (Knight, 2002): ¿Cómo determinamos quién es el hombre bueno? ¿Sobre qué base decidimos que una acción es correcta o incorrecta? ¿Existe alguna norma fundamental para la conducta? ¿Dónde encuentra apoyo esa norma: en el ser humano, o en una entidad externa? De esta manera, la ética está mayormente relacionada con juzgar, intenta determinar qué condiciones o experiencias son buenas o malas, qué rasgos del carácter son virtuosos o viciosos y que prácticas, instituciones y normas son correctas o equivocadas (Larson, 2003).

Canale (1999), comenta que la cosmovisión es un conjunto de ideas básicas acerca de la realidad que, como consecuencia de su naturaleza general y su amplio espectro, condiciona toda la gama del pensamiento y la acción de los hombres, funciona con presuposiciones que están directamente implícitas en el proceso por medio del cual los seres humanos comprendemos la realidad y nos relacionamos con ella. Así la cosmovisión es una perspectiva totalizadora acerca del origen, propósito y destino de la vida humana y del universo, que determina nuestros valores éticos y nuestra conducta diaria (Rasi, 1991). 
Fowler (1990), destaca que la cosmovisión no es opcional, todos los seres humanos pensamos y actuamos sobre la base de una cosmovisión, aunque no estemos conscientes de ello. Toda cosmovisión se apoya en el postulado básico o en la creencia fundamental que un individuo decide adoptar, al variar la premisa, varía la cosmovisión. Canale (1999), menciona que todos los seres humanos adquirimos inicialmente una cosmovisión mediante un proceso de asimilación cultural. Sin embargo, como resultado de algunos procesos de reflexión se puede elegir la cosmovisión que se desea adoptar, así es posible que se reemplacen por otros. Por lo tanto, cada ser humano está siempre construyendo y modificando su cosmovisión como resultado de las experiencias de la vida y de su reflexión sobre ellas (Fowler, 1990. pp. 6).

En la medida que la estructura conceptual que se construya sea coherente con los presupuestos fundamentales, la cosmovisión será defendible. Si los postulados no se comprenden o no se definen adecuadamente, la cosmovisión resultará defectuosa. Por esta razón, se evalúa dos cosmovisiones y cómo éstas proveen significado y propósito a la existencia humana en el contexto de la ética.

\section{Conceptualización de la cosmovisión bíblica y naturalista}

La cosmovisión bíblica está fundamentada en la Biblia. Fowler (1999), menciona siete pilares fundamentales de esta cosmovisión, a saber: (1) Dios es la realidad última, el centro y punto de referencia de todo, es la causa y el diseñador de la vida en todas sus formas, un ser que vive, se comunica con los seres humanos y busca relacionarse con ellos; (2) Dios se ha revelado a los seres humanos especialmente mediante la Biblia, que como revelación de Dios sienta las bases epistemológicas y éticas de la cosmovisión cristiana, fundamentalmente revelada por el Hijo; (3) Dios creó a los seres humanos a su propia imagen, lo cual coloca a los hombres y mujeres en una posición única de dignidad y valor; (4) el pecado ha dañado la creación de Dios al interrumpir el orden y el plan original, distorsionando las dimensiones física, mental, espiritual, emocional, social, como las relaciones y los valores; (5) Dios está librando un conflicto contra Satanás; (6) Dios ha tomado la iniciativa de restaurar la humanidad mediante la actividad redentora de Cristo; y (7) Dios ha asegurado la restauración final y la lleva a cabo.

El evolucionismo, que se basa en el naturalismo, plantea que la vida surgió por generación espontánea, un accidente, un azar del destino 
(Esperante, 2008), como consecuencia no dice nada sobre el sentido del universo ni de los seres humanos (Nuñez de Castro, 2007). Asimismo, considera la existencia de un intrincado proceso evolucionista, es decir, todas las formas de vida, proceden de las más simples, en este proceso sobrevive el más apto, aquel que tiene mejor capacidad de adaptación. Así, no hay meta final, ni ninguna fuerza que dirija la vida. Las mutaciones y la selección natural (productos del azar) operan ciegamente, conservando lo que funciona y descartando lo que no funciona.

\section{Concepción del hombre}

En la cosmovisión evolucionista, la persona no es más que el resultado del material genético en el proceso evolutivo de lo simple a lo complejo, un animal más, que deriva de algún primate que precedió al homo Sapiens (Kennedy, 1996), siendo la selección natural la explicación lógica del mecanismo evolutivo, donde sobrevive el más apto, el más fuerte, aquel que tiene mejor capacidad de adaptación. Tal afirmación provoca una ética competitiva, así, la persona debe estar preparada para adaptarse al medio y para competir con el prójimo con la finalidad de superarlo (Priora, 1989), porque los peces grandes se comen a los más chicos y éstos a los más pequeños. Según esta perspectiva, lo esencial en la vida es el poder, poder sobre los más débiles y la voluntad de ejercitarlo. Tal es la ley de la naturaleza, y el ser humano como parte del mundo natural, es más auténtico cuando se comporta como el resto de los animales (Provonsha, 1989).

En cambio, para la cosmovisión bíblica el hombre es imagen y semejanza de Dios (Gn 1:26, 27), un ser completo e indivisible, poco menor que los ángeles (Sal 8:5) y, como Wheeler (1998) destaca, representante de Dios sobre la creación inferior (Gn 1: 26, 28) y que vive en un ambiente de ayuda mutua (Gn 2:18). Este marco provee la base de la naturaleza relacional del ser humano en un ambiente de cooperación. Este sentido ético evita el desequilibrio de la competitividad por la cooperación en un ambiente de armonía (Armenteros, 2007).

\section{Concepción de la vida animal}

La evolución afirma que todas las formas de vida trazan su inicio desde los orígenes naturales de la materia sin vida. Así todas las especies y seres vivos evolucionaron a partir de un antecesor común, promoviendo la 
ética de la homogeneidad, es decir, que tanto animales como seres humanos son iguales (Powell, 2006). Desvalorizando a la persona como un mero animal que evolucionó. Esta aseveración genera varios problemas éticos en la persona, pues, siendo el hombre un animal, vive por instinto, buscando la satisfacción del placer por el mero hecho del placer (Brand, 1994), sin importar la persona, que sería tratada simplemente como un objeto.

En cambio, la cosmovisión bíblica cree que Dios creó todos los seres vivos, por lo menos a nivel de las especies y géneros (Gn 1:21, 24, 25). Y aunque existen similitudes entre el hombre y los animales (Rasi, 2004), las diferencias están profundamente enraizadas en el significado de ser "creado a imagen y semejanza de Dios". Así, la creatividad, el sentido estético, el uso de la inteligencia, la moral, el libre albedrío, la comunicación oral (Ekkens, 1994), la percepción de lo trascendental y esencialmente la capacidad de relacionarse con Dios como la expresión más elevada de su ser, son aspectos que diferencian al hombre de los animales (Hughes, 1989). Por lo cual, el hombre es un ser dotado por el Creador de libertad y autoridad ( $G$ n 1:26-28) que debe ejercer con responsabilidad, ante Dios, los hombres, y la naturaleza.

\section{Concepción de la conciencia moral}

La evolución trata de explicar y definir el origen de la moralidad en términos del relativismo cultural y sociobiología. El relativismo cultural arguye que cualquier cosa aprobada por un grupo cultural es correcto; lo que no sea aprobado por el grupo es incorrecto (Rachels, 2006). No existen principios fijos para guiar el desarrollo de códigos morales universales, ya que la cultura determina lo que es bueno y malo. Cada cultura desarrolla sus propias normas morales, y ninguna otra cultura tiene el derecho de juzgar el sistema de valores de otra cultura. Por lo tanto, no hay normas morales absolutas que se apliquen a toda la gente en todo lugar y tiempo.

La sociobiología es la aplicación de la teoría evolucionista al estudio de la conducta social animal y humana (Brand, 1998), analiza la base biológica de todo comportamiento social, incluyendo la moral, enseñando que todos los sistemas morales y religiosos existen simplemente porque ayudan a promover la supervivencia y la reproducción del grupo, argumentan que se puede explicar la existencia de cada religión o sistema de creencias importantes en el mundo en términos de selección natural y evolución, su impacto ético consiste en que la definición de "verdad" sólo puede ser definida como, "aquello que resulta", y no necesariamente lo que es verdadero. 
La cosmovisión bíblica acepta al hombre dotado de una conciencia que sería el asiento del libre albedrío, el filtro axiológico que regularía la praxis del hombre, como también el receptor de los mensajes divinos (Morales, 1984). Por lo tanto, el ser humano es un ser "racional-moral", así, no solamente percibe cómo son las cosas sino también se da cuenta de que las cosas deben ser de un cierto modo. Es consciente de la diferencia entre lo bueno y lo malo, entre lo correcto y lo equivocado.

\section{Las leyes y normas}

El naturalismo intenta explicar todo lo que existe en la naturaleza mediante las leyes naturales conocidas y, de esta manera, la ciencia debe explicarse naturalmente y ser sujeta a aprueba, mediante los criterios de nuestros cinco sentidos. Esto confiere autoridad a nuestros sentidos y al razonamiento humano. La consecuencia ética de esta formulación sería conceder autoridad a la persona para la búsqueda de soluciones o conseguirla en la naturaleza.

En contraposición, la cosmovisión bíblica sustenta que Dios es el Creador de todo el universo y de la vida (Gn 1, 2; Job 38:4-7; Sal 19; Jn 1:1-4; Col 1:16), Dios ha establecido un conjunto de leyes, y el universo opera de acuerdo a esas leyes. Las normas y leyes están presentes en la ética, como en la moral y la conciencia. Estas leyes emanan de la ley moral dada por el Supremo Legislador, la ética de la persona estará basada finalmente en la Palabra de Dios.

\section{Concepción del tiempo}

La cosmovisión evolucionista sostiene que la vida apareció hace 600 mil millones de años, el concepto de tiempo es concebido como cíclico, siendo el desarrollo de la historia con sus sociedades emergentes y decadentes, uniendo los parámetros de extensión y de repetición; se concluye que la presencia del ser humano en el mundo es sumamente insignificante y pasajera (Armenteros, 2007). La materia y la naturaleza son eternas y funcionan uniformemente en un sistema cerrado rigiéndose por el principio de causa-efecto y la historia es una corriente de eventos sin objetivos, que llevan en última instancia a un final destructivo, carente de sentido.

El resultado ético, al no percibirse un marco de origen (pasado) y destino (futuro) concreto, es vivir el momento, el día a día, ya que es su única oportunidad, pues todo comienza aquí y acaba aquí. Esto provoca el 
deseo de buscar la felicidad inmediata lo cual genera en el escapismo, la sexualidad descontextualizada solo por la búsqueda del placer por placer, la independencia egoísta. La inmediatez del presente mutila la responsabilidad. Una vida basada solo en el presente no tiene memoria, y por tanto, no precisa identidad.

En la cosmovisión bíblica el tiempo es lineal, existe un pasado y un futuro concreto, el tiempo adquiere valor. Por causa del efecto del pecado, la muerte existe. Por lo tanto, para el creyente, la redención es la única solución que rompe esta maldición. Este planteamiento da sentido a la historia y clarifica la participación de Dios en ella. Dios crea (protología), sustenta (providencia) y tiene un propósito final (escatología) para la historia del hombre. Dios está presente en todas las fases del desarrollo del universo. El resultado práctico es vivir éticamente con un llamado de redención y misión.

\section{Conclusión}

De acuerdo con la teoría evolucionista naturalista, el universo y la vida son un accidente, una sinrazón y significado en el cosmos, en la existencia del hombre o peor aún, en su ética, fuera de lo que el azar pudiera proporcionar.

La cosmovisión bíblica, en cambio, proporciona conceptos éticos claramente definidos. Los que proveen al hombre de una vida con sentido, utilidad, altos ideales, solidaridad, respeto, significado, trascendencia y misión.

Ambas cosmovisiones tienen un impacto en la ética y ése es el significado y propósito de la vida. La cosmovisión naturalista reduce la vida a cuestiones accidentales, negando, de plano, la función ética de la persona, como también, sus conceptos de valor y moral (Priora, 1989). La cosmovisión bíblica aporta sentido y claridad, otorgando a la persona valores que se desprenden de la máxima "hecho a imagen y semejanza de Dios", por consiguiente, la praxis y los valores morales tienen que ser realizados con responsabilidad ya que Dios, al final, traerá toda obra a juicio, sea buena o mala. 


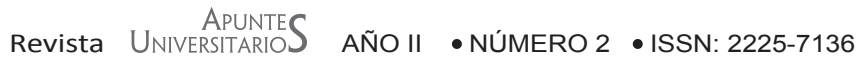

\section{Referencias}

Armenteros, V. (2007). Cosmovisión creacionista: la estructura de nuestro pensamiento. Ciencia de los Orígenes 74.

Brand, L. (1994). ¿Cuál es la relación entre la ciencia y la fe? Theologika 9, 1.

Brand, L. (2001). Fe y razón en la historia de la tierra: un paradigma de los orígenes de la tierra y de la vida mediante un diseño inteligente. Lima: Ediciones Theologika.

Cairus, A. (2009). Hombre en tratado de teología adventista del séptimo día. Buenos Aires: ACES.

Canale, F. (1999). La cosmovisión teológica y su influencia sobre la Iglesia Adventista del Séptimo día. Enfoques 11, 1 y 2.

Clark, J. (1982). Implicaciones filosóficas sobre la teoría de la evolución. Ciencia de los Orígenes 1.

Cremades, A. (2004). Creados a imagen de Dios: Hacia una antropología bíblica. Christ in the Classroom. Adventist Approaches to the Integration of Faith and Learning, Vol. 32. Silver Spring, MD: Institute for Christian Teaching Education Department.

De-Lucchi, F. y Alomía, M. (1989). Las especies del Génesis y la genética actual. Theologika 9, 2.

Ekkens, D. (1994). Los animales y los seres humanos: ¿¿son iguales?, Diálogo Universitario, 6,3.

Esperante, R. (2008). Abiogénesis y Exobiogénesis. Ciencia de los Orígenes 75.

Fowler, J. (1990). Hacia una cosmovisión cristiana, una perspectiva clara ante la vida y el destino. Diálogo Universitario 1.

Gulley, N. (2003) iCristo Viene! Un enfoque cristocéntrico de los eventos de los últimos días. Buenos Aires: ACES.

Hughes, O. (1989). Creados a imagen de Dios: un enfoque cristiano de la personalidad humana. Diálogo Universitario 2.

Kennedy, E. (1996), Buscando a los antepasados de Adán, Diálogo Universitario 8, 1.

Knight, G. (2002). Filosofía y educación, una introducción a la perspectiva cristiana. Colombia: Asociación publicadora interamericana.

Larson, D. (2003). Ética y Ciencia en la educación cristiana. Educación adventista 17.

Martines, C. (2011). Creación y evolución - origen, presente y destino; un estudio en contraste. Davarlogos 10, 1.

Morales, O. (1984). La conciencia humana y la ciencia. Ciencia de los Orígenes 9. 


\section{Joel Ricardo Turpo}

Núñez de Castro, I. (2007). Creación y sentido en un universo en evolución en evolución y cristianismo: un dialogo posible. Buenos Aires: Editorial Dunken.

Nyenhuis, G.y Eckman, J. (2002). Ética cristiana, un enfoque bíblico-teológico. Colombia: Editorial Unilit.

Priora, J. (1989). Principios evolucionistas en la filosofía de la educación. Ciencia de los Orígenes 22.

Provonsha, J. (1989). Bioética cristiana, decisiones racionales en asuntos de vida o muerte. Diálogo Universitario 1.

Rachels, J. (2006). Introducción a la filosofía moral. México: Fondo de cultura económica.

Rasi, H. (1991). Combatiendo en dos frentes, una respuesta adventista al secularismo y al neopanteísmo. Diálogo Universitario 1.

Romanenghi, E. (2006). Interrogantes sobre el sentido de la historia y otros ensayos. Buenos Aires, Ediciones Kairos.

Steger, C. (2004). Los dinosaurios y la inspiración. Revista adventista (Enero).

Veloso, M. (1980) El hombre, una persona viviente. Brasilia: Ediciones SALT.

Wheeler, G. (1998). Más allá de esta vida: Lo que Dios dice acerca de la vida, la muerte y la inmortalidad. Buenos Aires: ACES.

White, E. (1997). Mente, carácter y personalidad, tomo 1. Buenos Aires: Asociación Casa Editora Sudamericana. 